\title{
Experimental Study of The Insulating Effectiveness of Silicone Rubber Composites by Oxyacetylene Ablation Testing
}

\author{
Artem Andrianov ${ }^{1, *} \mathbb{D}$, Jungpyo Lee ${ }^{1} \mathbb{D}$, Gabriela Possa ${ }^{1}$, Hiterson de Oliveira Silva ${ }^{1}$ (D) \\ 1.Universidade de Brasília - Faculdade Gama - Brasília/DF - Brazil \\ *Correspondence author: andrianov@aerospace.unb.br
}

\begin{abstract}
The objective of this study was to characterize the thermal insulation efficiency of the silicone rubber reinforced composites by oxyacetylene torch. These composites reinforced by glass, carbon, ceramics and silica fibers were intended to be used as ablators in a low-thrust hybrid propulsion motor. The back-face temperature measurements were used as a criterion for insulation efficiency of the specimens, whose frontal face is subjected to the oxyacetylene flame for $40 \mathrm{~s}$. The paper includes the results of the ablation rate measurements and the influence of orientation of glass and carbon fibers relatively to the flame direction on the back-face temperature of the specimens.
\end{abstract}

Keywords: Thermal insulation; Ablation; Oxyacetylene torch; Silicone rubber.

\section{INTRODUCTION}

The presented study was motivated by the necessity of a prolonged fire testing of the low thrust hybrid propulsion motor developed at the University of Brasilia (Andrianov et al. 2015). The required operation time of the motor should be at least $40 \mathrm{~s}$, which requires special measures to ensure thermal protection of the motor casing. Thermal protection for hybrids can be adopted from solid propellant rocket motors. In solid propulsion systems, it is performed by internal insulation, which functions as a heat barrier primarily through the mechanism of ablation (Twichell and Keller Junior 1976). Generally, insulators for solid rocket motors are identified by filler (reinforcement) and matrix (binder); the latter identifies the class of insulation material, which can be thermosetting or elastomeric plastic. The most common thermosetting matrix is phenolic resin, a char-yielding material with good temperature resistance, but with relatively low elasticity (Ahmed 2009), which limits its application for heat insulation of motor casings experiencing high deformations. Thus, body insulations are usually elastomeric composites providing strain tolerance (Youren 1971).

According to an extensive literature review on elastomeric heat-shielding materials for rocketry (Donskoy 1996), the most appropriate elastomeric heat shielding matrices are nitrile-butadiene, ethylene-propylene and silicone organic rubbers.

Received: Feb. 10, 2020 | Accepted: Sep. 14, 2020

Peer Review History: This is a peer reviewed version of selected paper presented the $2^{\circ}$ Congresso Aeroespacial Brasileiro occurred in 16 -19 September of 2019 at Universidade Federal de Santa Maria, Santa Maria/RS, Brazil.

Section Editor: André Luis da Silva

This is an open access article distributed under the terms of the Creative Commons license. 
Fabrication of insulators from the first two elastomers requires a complex technological process including vulcanization at elevated temperatures. Sophisticated manufacturing process may affect the main advantages of a hybrid propulsion technology, such as flexibility and architecture simplicity (Mazetti et al. 2016). At the same time, a wide range of organic silicones does not require complex technological process and can be vulcanized at room temperatures. According to data provided by Donskoy (1996), erosion resistance for silicone elastomer filled with carbon (density $1.16 \mathrm{~g} / \mathrm{cm}^{3}$, ablation rate $0.020 \mathrm{~mm} / \mathrm{s}$ ) is slightly greater than for ethylene-propylene rubber filled with asbestos fiber $\left(1.23 \mathrm{~g} / \mathrm{cm}^{3}, 0.015 \mathrm{~mm} / \mathrm{s}\right)$, polypropylene rubber filled with carbon $\left(1.24 \mathrm{~g} / \mathrm{cm}^{3}\right.$, $0.015 \mathrm{~mm} / \mathrm{s})$ and silica $\left(1.45 \mathrm{~g} / \mathrm{cm}^{3}, 0.019 \mathrm{~mm} / \mathrm{s}\right)$.

The extensive literature review by Natali et al. (2016) covers all necessary information on types, technology, testing techniques and application of ablative materials in the aerospace industry, including polysiloxanes (or silicones). According to these authors, silicones are effective matrices for thermal protections systems due to: 1) relatively low density $1-1.2 \mathrm{~g} / \mathrm{cm}^{3} ; 2$ ) high thermal resistance (owing to high binding energy of silicon-oxygen bond); 3) capability of yielding siliceous/carbonaceous char; 4) high oxidation resistance in comparison to other char yielding polymers. Thermal resistance of silicones is supported by high binding energy of Si-C bond in comparison with $\mathrm{C}$-C bond in the main chain of hydrocarbon elastomers, possibility to rearrange molecular structure under thermal influence and to form cyclic molecular compounds (Donskoy 1996). Polymers with rings in the polymer chain form a high percentage of char during pyrolysis, which improves erosion resistance of insulator (Schmidt 1969). Besides that, a char layer is supported by a silicone backbone structure even in case when a char layer experiences severe conditions of pressure and temperatures up to $1000^{\circ} \mathrm{C}$ in the conditions of induced air combustion chamber (Oyumi 1998). More detailed review for thermal degradation mechanism of polysiloxanes is given by Zhou et al. (2006).

It should be noted that high thermal insulation characteristics of silicone elastomers (such as a lower rate of ablation and higher insulation index tested in oxyacetylene flame in comparison to other elastomers: butadiene acrylonitrile, chloroprene, urethane etc.) have been known for a long time (Schmidt 1965).

At some conditions of heating, decomposition of silicone is slower than in phenolic resin (Favaloro 2000): at 700 ${ }^{\circ} \mathrm{C}$, the volatilized portion for silicone is near $20 \%$ and for phenolic resin is near $50 \%$. As the experimental study by Chapman (1966) shows, the ablative material with a silicone resin base produced the highest performance in a moderate range of conditions (heat rate below $1.14 \mathrm{MW} / \mathrm{m}^{2}$ and dynamic pressure below $2.4 \mathrm{kN} / \mathrm{m}^{2}$ ) provided by electric-arc-heated gas stream in comparison to phenolic and epoxy base materials. Tests with use of small-scale motor burning kerosene-oxygen showed that silicone is more thermally stable and more preferred polymer matrix than the phenolic resin for ablative components of vertical launch systems subjected to exhaust plume from solid rocket motors (Koo et al. 2011; Miller et al. 1994).

Yang et al. (2013a) showed that the silicone rubber filled with silica and carbon fibers in oxyacetylene flame yields the ablative layer, whose thermo-oxidative stability is better than that of unfilled rubber due to formation of silica, silicon carbide and aromatic carbon, which transforms into inorganic carbon. Ablative properties can be improved by reinforcement of silicone rubber with various inorganic fibers: not only carbon (Kim et al. 2008; 2011), but also silicon carbide (Zhang et al. 2016), silicate ceramic (Yu et al. 2014; Zhou et al. 2015), zirconium carbide (Yang et al. 2013b) and others. However, the authors compare efficiency of reinforced composites with a virgin silicone rubber, and it is not clear how various types of fillers affect the insulating effectiveness of silicone composite.

According to Donskoy (1996), there are few information about rubbers reinforced with fabrics. The experimental data on insulating effectiveness for various types of fillers in silicone matrix and elevated heat fluxes are given by Koo et al. (2011).

The objective of the presented study is to fill the data gap in the range of moderate heat fluxes $0.01-0.1 \mathrm{MW} / \mathrm{m}^{2}$, which are inherent to low-thrust hybrid propellant motors (Nunes et al. 2017). The back-face temperature measurements are used as a criterion for insulation efficiency of the silicone rubber specimens, whose frontal face is subjected to oxyacetylene flame for $40 \mathrm{~s}$. The specimens were reinforced with four types of widely available fabrics and tapes based on glass, carbon, ceramics and silica fibers. Other objectives of the study are the comparison of the mass ablation rate of silicone composites and evaluation of back-face temperature of the specimens with parallel and perpendicular orientation of glass and carbon fibers relatively to the oxyacetylene flame direction. 


\section{MATERIAL AND METHODS}

The characteristics of silicone rubber composites reinforced by glass, carbon, ceramic and silica fibers with perpendicular and parallel orientation in relation to flame direction are given in Tables 1 and 2, respectively. The silicone rubber was obtained by mixture of polydimethylsiloxanes with inorganic fillers (delivering conditions) and copper phthalocyanine. Polydimethylsiloxane was used as a matrix due to low cost and simple processing. Ablation characteristics of the silicone rubber in conditions of burning of liquid nitrous oxide and solid paraffin fuel grain (conditions of the low-thrust hybrid propellant rocket motor) are given by Milhomem et al. (2017).

Table 1. Silicone rubber composites with perpendicular orientation of plies in relation to flame direction.

\begin{tabular}{|c|c|c|c|c|}
\hline \multirow{2}{*}{ Name } & \multicolumn{2}{|c|}{ Reinforcement } & \multicolumn{2}{|c|}{ Specimen } \\
\hline & Description & Superficial density $\left[\mathrm{g} / \mathrm{m}^{2}\right]$ & Thickness (mm) & Density $\left[\mathrm{g} / \mathrm{cm}^{3}\right]$ \\
\hline MA & Fiberglass mat 450 (E-glass) & 450 & 6.8 & 1.56 \\
\hline 320 & Unidirectional carbon tape 32Ч & 332 & 6.5 & 1.45 \\
\hline $\mathrm{Bl} 52$ & Bidirectional carbon tape BI52 & 200 & 6.4 & 1.46 \\
\hline 110 & Fiberglass fabric 110 (E-glass) & 110 & 6.6 & 1.58 \\
\hline 200 & Fiberglass fabric 200 (E-glass) & 200 & 6.4 & 1.64 \\
\hline 300 & Fiberglass fabric 300 (E-glass) & 300 & 6.5 & 1.72 \\
\hline 600 & Fiberglass fabric 600 (E-glass) & 600 & 5.9 & 1.65 \\
\hline TSI & Silica fiber fabric TS1000 & 1280 & 6.4 & 1.70 \\
\hline TCE & Ceramic fiber tape FC1200 & 1460 & 7.0 & 1.54 \\
\hline
\end{tabular}

The specimens were manufactured by manual lay-up technology at room temperatures, then cut to dimensions of $50 \pm 1$ by $50 \pm 1 \mathrm{~mm}$. The thickness of specimens was $6.35 \pm 0.41 \mathrm{~mm}$. It was provided by appropriate number of plies in the specimens, whose fibers were oriented perpendicularly to flame direction (hereinafter referred to as perpendicular specimens). At least five replicates of each type of specimen were tested. The thickness of specimens with parallel-toflame orientation of fibers (hereinafter referred to as parallel specimens) was provided by cutting. It is necessary to note that parallel specimens practically did not have flexural rigidity, thus they were additionally reinforced by gluing of metal sheets on the back-face.

Table 2. Silicone rubber composites with parallel orientation of plies in relation to flame direction.

\begin{tabular}{|c|c|c|c|c|}
\hline \multirow{2}{*}{ Name } & \multicolumn{2}{|c|}{ Reinforcement } & \multicolumn{2}{|c|}{ Specimen } \\
\hline & Description & Superficial density, $\mathrm{g} / \mathrm{m}^{2}$ & Thickness, mm & Density, $\mathrm{g} / \mathrm{cm}^{3}$ \\
\hline $110-11$ & Fiberglass fabric 110 (E-glass) & 110 & 6.4 & 1.48 \\
\hline 200-II & Fiberglass fabric 200 (E-glass) & 200 & 6.5 & 1.51 \\
\hline 300-11 & Fiberglass fabric 300 (E-glass) & 300 & 6.4 & 1.46 \\
\hline 32U-II & Unidirectional carbon tape 32บ & 332 & 6.4 & 1.42 \\
\hline BI52-II & Bidirectional carbon tape BI52 & 200 & 6.8 & 1.35 \\
\hline
\end{tabular}


The methodology described in ASTM standard (ASTM 2008) was used as a reference, but with some alterations to attend the objectives of the study (considering availability of appropriate welding equipment on Brazilian market).

The scheme of the oxyacetylene test-bench is shown in Fig. 1a. The specimen is hold by four screws equipped with silicone separators to diminish the loss of heat. The specimen holder has two positions in vertical direction. The lower position is used for installation of specimen in the holder, coupling of thermocouples in adapters and setting of neutral flame in oxyacetylene torch. For a fire testing, the holder is displaced manually to upper position and the tip of lateral thermocouple passes through the flame determining a starting point of burning time. Since the heat fluxes in low-thrust hybrid propellant motors are moderate (Nunes et al. 2017), the welding torch (whose characteristics are given in Table 3) adopted for the test-bench had been selected on the basis of the relatively low heat flux. The same settings were used for all tests: the length of internal cone of the neutral flame was $9 \mathrm{~mm}$, the distance between front face of specimen and torch tip was $9 \mathrm{~mm}$. In spite of the fact that the test-bench could be equipped with five thermocouples (Fig. 1b), the back-face temperature was measured by three K-type thermocouples Omega KMQXL-062U-6 with response time 0.3 s (diameter $1.6 \mathrm{~mm})$.
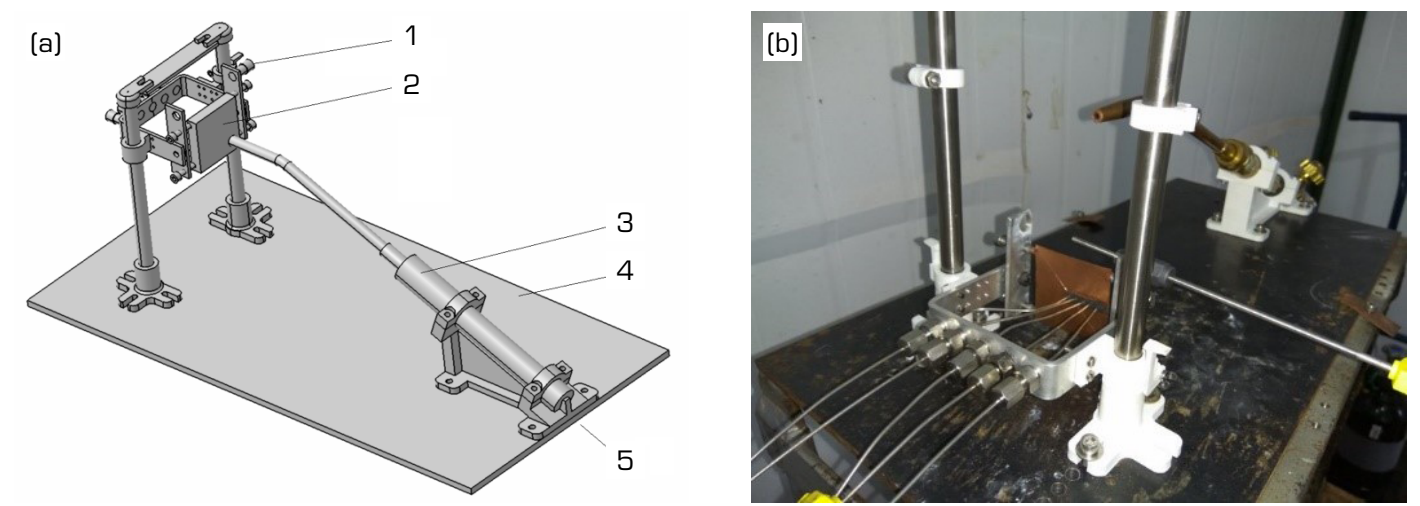

Figure 1. The oxyacetylene test-bench: a) the scheme; 1 - specimen holder; 2 - specimen; 3 - torch; 4 - test-bench plate; 5 - gas hose inlet; b) photograph of the test-bench equipped with five thermocouples for back-face measurements and one lateral thermocouple for timing of burning.

Table 3. Characteristics of welding torch Condor 201 AC\#9 adapted for oxyacetylene test-bench.

\begin{tabular}{|c|c|c|c|}
\hline \multicolumn{2}{|c|}{ Pressure $\left[\mathrm{kgF} / \mathrm{cm}^{2}\right]$} & \multicolumn{2}{|c|}{ Flow rate $[1 / h]$} \\
\hline Oxygen & Acetylene & Oxygen & Acetylene \\
\hline $0.10-0.40$ & $0.20-0.40$ & 220 - 270 & $210-250$ \\
\hline
\end{tabular}

The tip of the first thermocouple was installed in the center of specimen's back-face (the central point $0 \mathrm{~mm}$ ) in such way that the axis of flame would pass through this central point. The tips of the other two thermocouples were displaced along specimen's back-face in lateral direction on distance 4 and $8 \mathrm{~mm}$ from the central point. To immobilize the tip of a thermocouple on the back-face of a specimen, the latter was equipped with a silicone rubber strip with five conducting holes spaced $4 \mathrm{~mm}$ apart (Fig. 2a). Initial moment of burning time was determined by the thermocouple Omega KMQXL-125U-6 with response time $0.4 \mathrm{~s}$ (diameter $3.2 \mathrm{~mm}$ ), whose tip was installed above the upper edge of a specimen. When the specimen holder dislocates from the lower to an upper position, the thermocouple tip passes through a flame providing an impulse of temperature rise and establishing a starting point. The data from all thermocouples were recorded by data acquisition system Lynx ADS2000. 
(a)

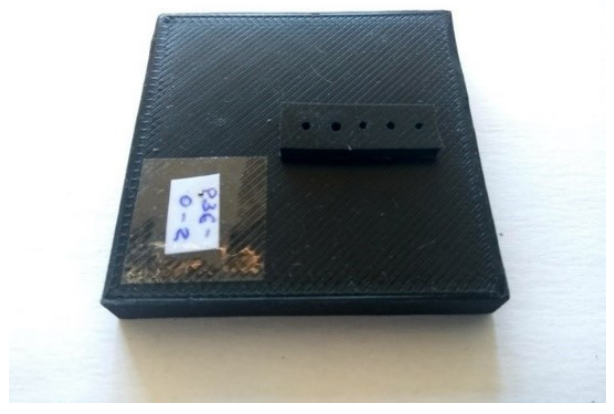

(b)

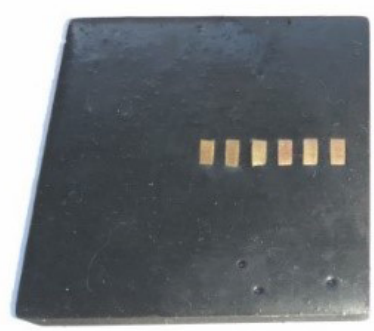

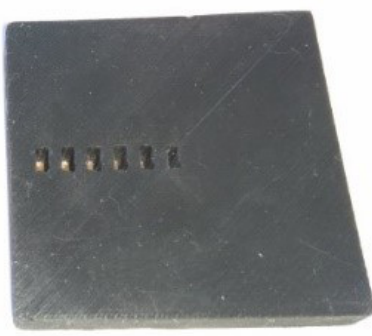

Figure 2. The specimens used in the study: a) the typical specimen of silicone rubber composite; b) the specimen for characterization of oxyacetylene flame (back-face is on the right-hand side).

Since the tested composites were intended to be used as a heat insulator for the low-thrust hybrid propellant motor with operation time no less than $40 \mathrm{~s}$, the same period of time was accepted for the oxyacetylene ablation testing.

Mass ablation rate of specimens was calculated by Eq. 1.

$$
a=\frac{m_{o}-m_{f}}{\delta \tau}
$$

where: $m_{\mathrm{o}}$ is the initial mass in $\mathrm{g}$ of the specimen; $m_{\mathrm{f}}$ is the mass in $\mathrm{g}$ of the specimen after burning time $\delta \tau$ (in seconds).

A special specimen was prepared for determination of incident heat flux from oxyacetylene heat source. The specimen was made from a material with relatively low thermal conductivity (silicone rubber) and had a shape of a plate with six rectangular through holes spaced $4 \mathrm{~mm}$ apart (Fig. 2b). Thin copper sheets with nominal thickness 0.56 mm were embedded into the holes. The specimen front-face was in the same plane as a front surface of the copper sheets, whose back surface was in contact with thermocouple tips. The temperature measured on the back surface is a result of heat transfer through the thickness of a copper with known thermal properties. The heat transfer through silicone rubber was ignored, because of its low thermal conductivity in comparison with copper and the specimen was exposed to oxyacetylene flame for a short period of time.

Heat flux in the first approximation was calculated by the heat diffusion equation (Eq. 2) for the case of unidirectional heat transfer (Barros et al. 2009):

$$
\ddot{q}_{x}=\rho C_{p} \delta x \frac{\delta T}{\delta \tau}
$$

where: $\rho$ is density of copper, $\mathrm{kg} / \mathrm{m}^{3} ; C_{p}$ is specific heat, $\mathrm{J} /(\mathrm{kg} \cdot \mathrm{K}) ; \delta x$ is sheet thickness, $\mathrm{m} ; \delta T$ is the difference between the initial temperature and the temperature after burning period $\delta \tau$ in seconds, K. The maximum burning time $\delta \tau$ for the characterization of incident heat flux was $7 \mathrm{~s}$.

\section{RESULTS AND DISCUSSION}

Figure 3a shows one of the five plots of temperature vs time from oxyacetylene flame characterization tests. These data were used for calculation of the heat flux by Eq. 2 for one of the particular coordinates of specimen and burning intervals $\delta T: 0-1 \mathrm{~s}$, $0-2 \mathrm{~s}, 0-3 \mathrm{~s}, 0-5 \mathrm{~s}$ and $0-7 \mathrm{~s}$ (Fig. 3b). Heat transfer from flame to specimen occurs by convection and radiation and depends on temperature of external surface of copper sheets. After observation of data in Fig. 3a, the interval of 2 to $7 \mathrm{~s}$ was accepted for calculation of incident heat flux, whose mean values from five measurements are: $114.5 \pm 24 \mathrm{~kW} / \mathrm{m}^{2}$ for the central point $0 \mathrm{~mm}$, $44 \pm 14.5 \mathrm{~kW} / \mathrm{m}^{2}$ for the central point $4 \mathrm{~mm}, 18 \pm 4.9 \mathrm{~kW} / \mathrm{m}^{2}$ for the central point $8 \mathrm{~mm}$. 
(a)

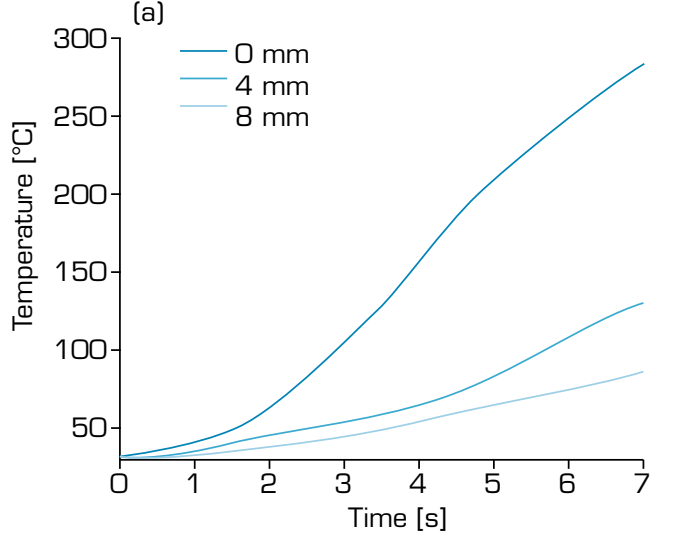

(b)

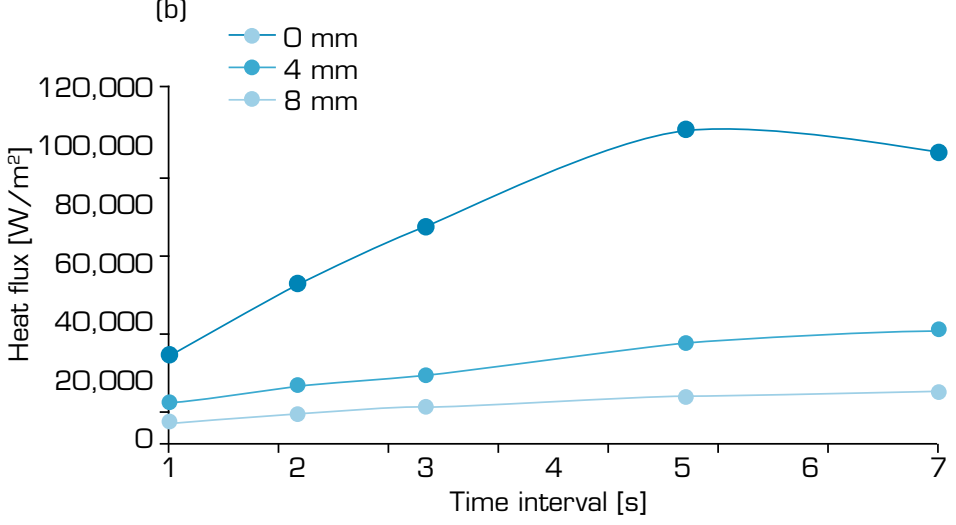

Figure 3. The results of oxyacetylene flame characterization: a) the measured back-face temperature; b) the calculated incident heat flux.

According to the results on insulating effectiveness of the tested specimens reinforced by fibers perpendicularly to direction of oxyacetylene flame (Table 4), the maximum back-face temperature after $40 \mathrm{~s}$ is in the range $60-85^{\circ} \mathrm{C}$ for all tested specimens. The ranges of temperature for the points 4 and $8 \mathrm{~mm}$ are $50-70^{\circ} \mathrm{C}$ and $50-65^{\circ} \mathrm{C}$ respectively, that indicates practically the same insulating effectiveness of the specimens reinforced by various fibers at the given testing conditions. However, reasons of the similar effectiveness are not the same for all specimens.

Table 4. Insulating effectiveness of the silicone rubber composites.

\begin{tabular}{|c|c|c|c|c|c|c|c|c|}
\hline \multirow{3}{*}{$\begin{array}{c}\text { Fiber } \\
\text { material }\end{array}$} & \multirow{3}{*}{ Type } & \multirow{3}{*}{$\begin{array}{l}\text { Mean } \\
\text { thickness } \\
\text { (mm] }\end{array}$} & \multicolumn{6}{|c|}{ Temperature after $40 \mathrm{~s}$ for three points of measurements $\left({ }^{\circ} \mathrm{C}\right)$} \\
\hline & & & \multicolumn{2}{|c|}{$0 \mathrm{~mm}$} & \multicolumn{2}{|c|}{$4 \mathrm{~mm}$} & \multicolumn{2}{|c|}{$8 \mathrm{~mm}$} \\
\hline & & & Mean & Deviation & Mean & Deviation & Mean & Deviation \\
\hline \multirow{5}{*}{ E-glass } & MA & 6.8 & 58.4 & 1.3 & 51.0 & 2.2 & 50.1 & 1.5 \\
\hline & 110 & 6.6 & 73.4 & 1.0 & 58.5 & 2.3 & 54.2 & 2.5 \\
\hline & 200 & 6.4 & 72.0 & 3.5 & 60.7 & 6.6 & 50.9 & 0.3 \\
\hline & 300 & 6.5 & 66.4 & 1.9 & 53.9 & 3.2 & 55.0 & 2.7 \\
\hline & 600 & 5.9 & 85.8 & 0.5 & 70.3 & 1.8 & 65.6 & 4.2 \\
\hline \multirow{2}{*}{ Carbon } & $32 \cup$ & 6.5 & 67.5 & 3.7 & 61.3 & 4.3 & 59.8 & 6.3 \\
\hline & Bl52 & 6.4 & 74.4 & 8.1 & 65.8 & 6.6 & 63.6 & 7.1 \\
\hline Silica & TSI & 7.0 & 72.9 & 5.4 & 62.0 & 3.0 & 60.4 & 2.3 \\
\hline Ceramic & TCE & 6.5 & 79.0 & 2.3 & 67.3 & 4.9 & 63.9 & 5.0 \\
\hline
\end{tabular}

It is known that axial thermal conductivity for E-glass fiber is one order less than for a standard-modulus polyacrylonitrile carbon fiber (Zweben 2006). At the same time, the depth of crater in fiberglass specimens is greater than in carbon or ceramic fiber specimens (Fig. 4). The specimens reinforced by glass and carbon fibers (Fig. $4 \mathrm{a}$ and $4 \mathrm{~d}$, respectively) were subjected to flame for $58 \mathrm{~s}$. As a result, the former specimen has suffered dilatation and the minimal measured thickness through the bottom of the crater was $5.4 \mathrm{~mm}$. At the same time, the latter specimen did not swell and the minimal residual thickness was $6.4 \mathrm{~mm}$. Therefore, for the given testing conditions, lower thermal conductivity of fiberglass specimens is compensated by small residual thickness, and for carbon fiber specimens, higher thermal conductivity is compensated by greater residual thickness. 

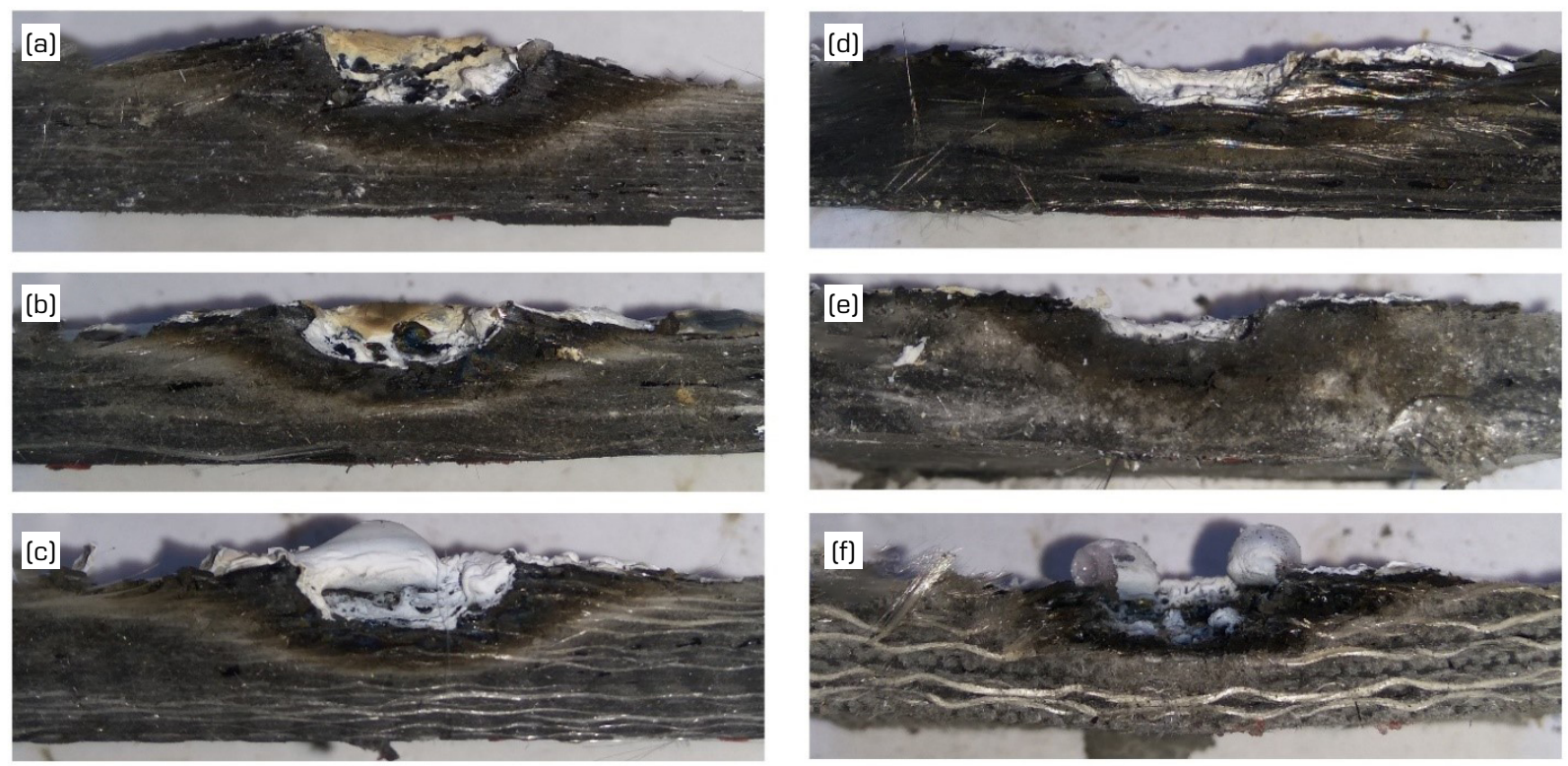

Figure 4. The cross-sections through the center of tested silicone rubber specimens: a) fiberglass 110 (burning time $\Delta \tau=58 \mathrm{~s}) ;$ b) fiberglass $600(\Delta \tau=41 \mathrm{~s})$; c) fiberglass $300(\Delta \tau=41 \mathrm{~s})$; d) carbon fiber $32 \mathrm{U}(\Delta \tau=58 \mathrm{~s})$; e) ceramic fiber TCE $(\Delta \tau=41 \mathrm{~s})$; f) silica fiber TSI $(\Delta \tau=41 \mathrm{~s})$.

It is important to note that ablation rate by mass is lower for fiberglass specimens (Table 5). It can be explained by the effect of full reflection of flame from the front surface of specimen when the crater in specimen takes the semiellipsoid form. In the carbon fiber specimens, such shape of crater does not form (Fig. 4d) and the flame is distributed over the front face of specimen (Fig. 5a). The burning occurs over all front face of specimen and the mass losses are higher. Half of the specimens reinforced with ceramic tape did not have the effect of flame reflection and the shape of crater does not look like profound hemiellipsoid (Fig. 4e). In most of the specimens, the full reflection of flame (Fig. 5c) occurs after some time, which is difficult to determine accurately due to transition effect (Fig. 5b).

Figure 6 shows data on temperature measurement on the back-face of specimens, whose fibers have parallel or perpendicular orientation in relation to flame direction. According to the data in Fig. 6, the temperature in the specimens, whose fibers have parallel orientation in relation to flame direction (marked with "-11-"), increases much faster than in specimens with perpendicular orientation of fibers. In the parallel specimens reinforced by fabric, at least half of the fibers is arranged along the thickness of specimen. This portion of fibers serves as a heat conductor, since heat propagates easily along the length of the fibers. As thicker is a fiberglass fabric, as better it conducts a heat in parallel specimens: the temperature on back-face of the specimens 300 is growing faster than on back-face of the specimens 110 and 200 (Fig. 6a). The temperature rises faster in specimens with parallel orientation of carbon fibers than in fiberglass specimens with the same orientation due to higher heat conductivity of carbon (Fig. 6b).

For parallel specimens reinforced with carbon fibers, burning time was reduced to $30 \mathrm{~s}$. In case of burning time above $30 \mathrm{~s}$, these specimens start to deflect due to low flexural rigidity and thermocouples escape from their previous positions. Carbon fibers oriented along the thickness of ablator demonstrate increased resistance to erosion because of high melting temperature of carbon and the roots of the fibers are held by nonheated matrix. After $30 \mathrm{~s}$ of burning, there are no sign of thickness reduction in specimens reinforced by carbon fibers in comparison to fiberglass specimens (Fig. 7). High thermal conductivity of carbon is not compensated anymore by greater thickness like in specimens with perpendicular orientation of fibers, therefore the temperature on the back-face of parallel specimens grows faster (Fig. 6a).

In perpendicular specimens, there are no fibers oriented along the thickness. The heat from front-face to back-face of specimen propagates through the thickness of fibers and silicone rubber. Since heat conductivity for silicone rubber is lower than for fibers, the temperature growth is slower for specimens with perpendicular orientation of fibers. It explains the least temperature in perpendicular specimen MA reinforced by fiberglass mat (Fig. 6a). Here, fibers are distributed arbitrary in various directions in the plane of ply, which is perpendicular to flame direction. 
Table 5. Ablation rates of the tested silicone rubber composites.

\begin{tabular}{|c|c|c|c|c|c|c|}
\hline \multirow{2}{*}{$\begin{array}{c}\text { Fiber } \\
\text { material }\end{array}$} & \multirow{2}{*}{ Type } & \multirow{2}{*}{$\begin{array}{c}\text { Mean } \\
\text { thickness, mm }\end{array}$} & \multicolumn{2}{|c|}{ Ablation rate for $40 \mathrm{~s}, \mathrm{~g} / \mathrm{s}$} & \multicolumn{2}{|c|}{ Full flame reflection time, $s$} \\
\hline & & & Mean & Deviation & Mean & Deviation \\
\hline \multirow{5}{*}{ Glass } & MA & 6.8 & 0.017 & 0.001 & 24.9 & 3.8 \\
\hline & 110 & 6.6 & 0.017 & 0.003 & 28.7 & 11.2 \\
\hline & 200 & 6.4 & 0.015 & 0.002 & 20.3 & 4.0 \\
\hline & 300 & 6.5 & 0.013 & 0.003 & 25.1 & 3.8 \\
\hline & 600 & 5.9 & 0.015 & 0.002 & 28.5 & 5.9 \\
\hline \multirow{2}{*}{ Carbon } & Зอบ & 6.5 & 0.027 & 0.003 & - & - \\
\hline & $\mathrm{Bl52}$ & 6.4 & 0.027 & 0.008 & - & - \\
\hline Silica & TSI & 6.4 & 0.013 & 0.003 & 29.2 & 0.2 \\
\hline Ceramic & TCE & 7.0 & 0.025 & 0.002 & $30.3^{*}$ & $0.3^{*}$ \\
\hline
\end{tabular}

* data for two specimens only.
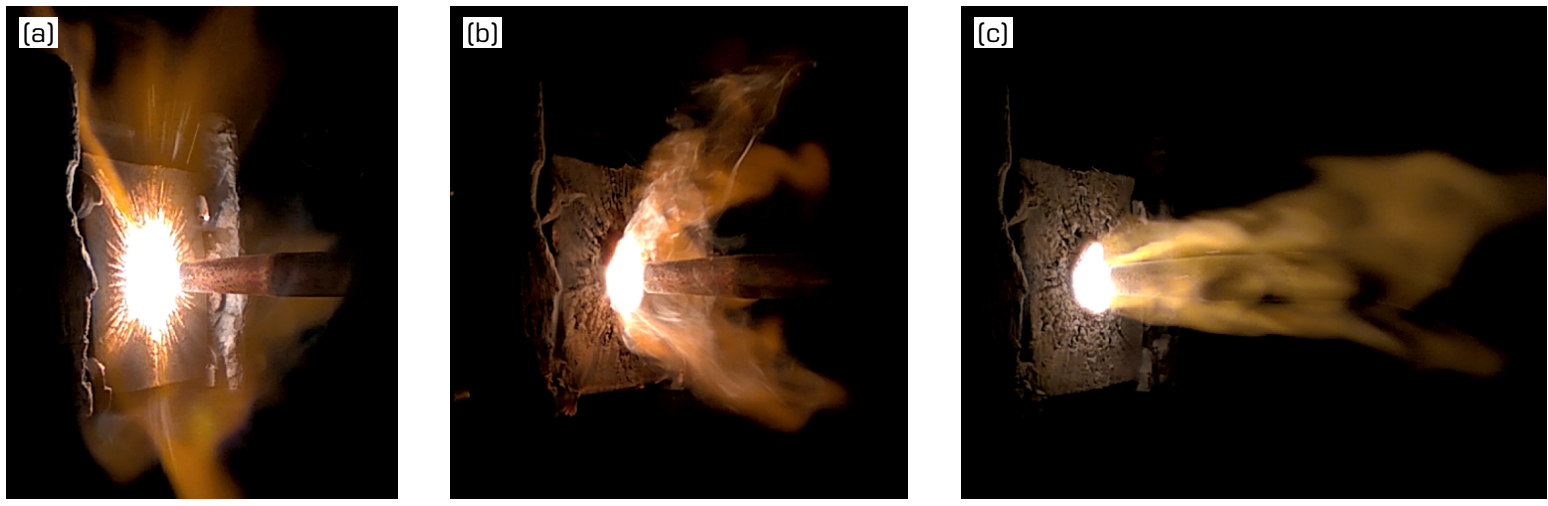

Figure 5. The effect of flame reflection for the same specimen MA: a) no flame reflection; b) partial reflection of flame; c) full reflection of flame.

(a)

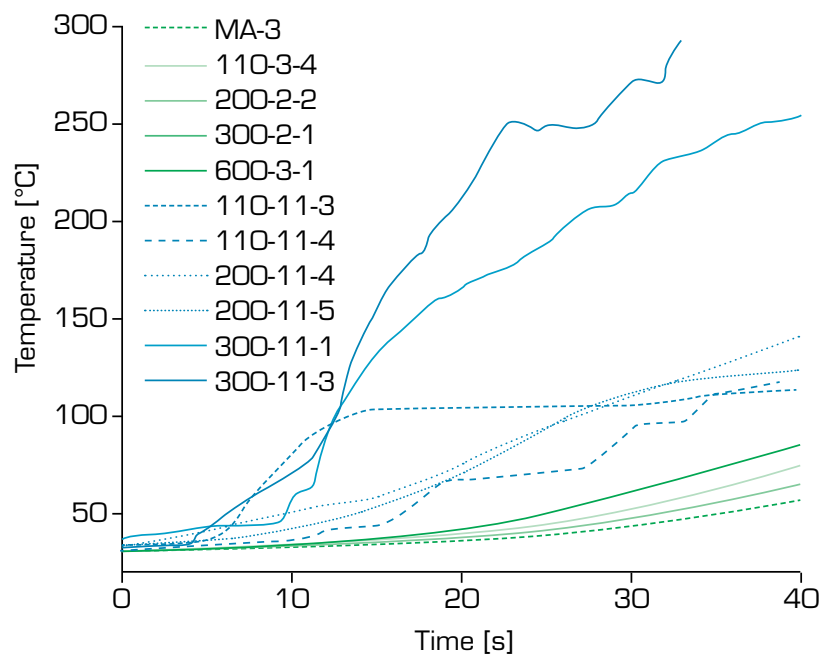

(b)

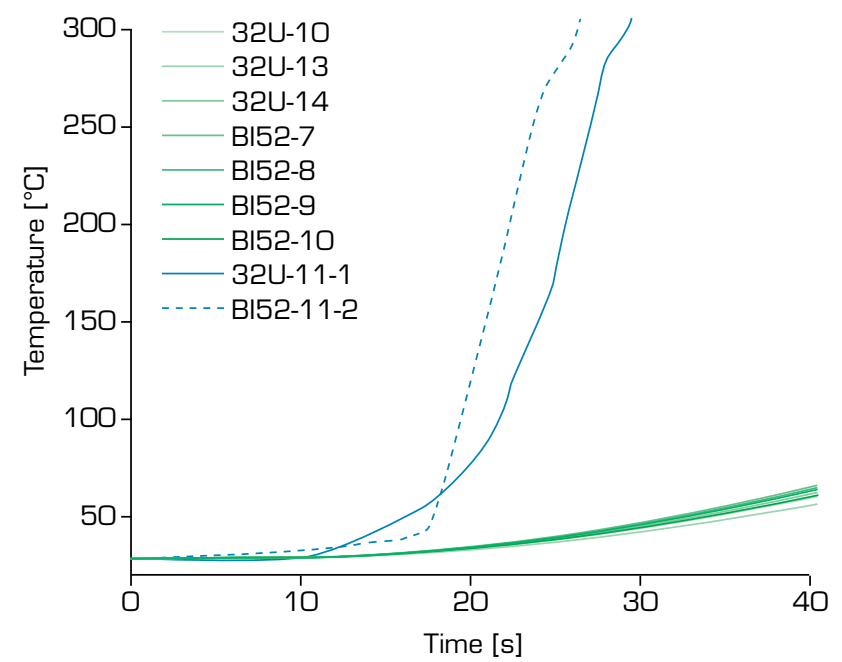

Figure 6. Temperature measurements on back-face central point $0 \mathrm{~mm}$ of the selected specimens reinforced by fiberglass (a) and carbon (b) fibers with parallel (blue curves) and perpendicular (green curves) orientation in relation to flame direction. 

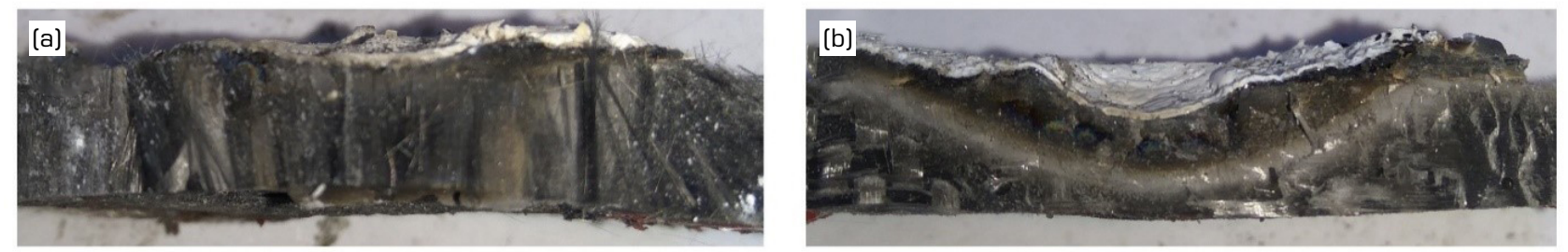

Figure 7. The cross-sections through the center of tested specimens with parallel orientation of fibers in relation to flame direction: a) 32U-11 (burning time $\Delta \tau=30 \mathrm{~s}$ ); b) fiberglass 200-11 ( $\Delta \tau=30 \mathrm{~s}$ ).

\section{CONCLUSION}

The reinforcement of silicone rubber composites with fiberglass fabric or carbon tape in parallel-to-flame direction is impractical due to low insulating effectiveness. After $40 \mathrm{~s}$ of burning, the back-face temperature of perpendicular specimens reinforced by E-glass is in the range $58.4-85.8^{\circ} \mathrm{C}$, while in parallel specimens it exceeds $100^{\circ} \mathrm{C}$. For carbon-reinforced composites, this difference is even greater due to high thermal conductivity of carbon: the back-face temperature of perpendicular specimens is in the range $67.5-74.4^{\circ} \mathrm{C}$ after $40 \mathrm{~s}$ of burning, whereas in parallel specimens the temperature is greater than $350{ }^{\circ} \mathrm{C}$ after $30 \mathrm{~s}$ of burning.

The comparison of mass ablation rate of parallel specimens was prejudiced by the effect of flame reflection that was observed after 20-30 s of burning in all composites except those reinforced with carbon and ceramic fibers. The latter specimens had higher mass ablation rate $0.025-0.027 \mathrm{~g} / \mathrm{s}$ than fiberglass and silica specimens, whose mass ablation rate was in the range of 0.013 to $0.017 \mathrm{~g} / \mathrm{s}$.

For the given conditions of tests (heat flux from the oxyacetylene torch $114.5 \pm 24 \mathrm{~kW} / \mathrm{m}^{2}$ and burning time $40 \mathrm{~s}$ ), the tested silicone rubber composites reinforced with E-glass, carbon, silica and ceramic fabrics (or tapes) with perpendicular orientation of plies in relation to the flame direction demonstrated almost the same insulation effectiveness. The least back-face temperature $58.4 \pm 1.3^{\circ} \mathrm{C}$ was observed in specimens MA reinforced with fiberglass mat (density $1.56 \mathrm{~g} / \mathrm{cm}^{3}$ ); however, the mean thickness of these specimens was slightly higher than in other specimens except those reinforced by ceramic fibers. In spite the fact that the back-face temperature $67.5 \pm 3.7^{\circ} \mathrm{C}$ in specimens reinforced by carbon tape 32U was higher than in MA specimens, their principal advantage is the least mean density $1.45 \mathrm{~g} / \mathrm{cm}^{3}$.

It is evident that for low-cost systems, like low-thrust hybrid propulsion rocket motors with relatively short operation time, the less expensive fiberglass composites could be applied for fabrication of internal insulation with insignificant losses in efficiency. However, their efficiency has to be experimentally confirmed in conditions of hybrid propellant rocket motor.

\section{AUTHORS' CONTRIBUTION}

Conceptualization: Andrianov A.; Formal Analysis: Andrianov A.; Investigation: Andrianov A., Lee J., Possa G. and Silva H.O.; Methodology: Andrianov A. and Lee J.; Writing - Original Draft: Andrianov A.

\section{DATA AVAILABILITY STATEMENT}

All the datasets were generated during the current study.

\section{FUNDING}

Fundação de Apoio à Pesquisa do Distrito Federal. Grant No: 0193.000895/2015

http://doi.org/10.13039/501100005668 


\section{ACKNOWLEDGEMENTS}

To the Organization Committee of II Congresso Aeroespacial Brasileiro.

\section{REFERENCES}

Ahmed AF (2009) Thermal insulation by heat resistant polymers (PhD thesis). Montreal: Concordia University. In English.

Andrianov A, Shynkarenko O, Bertoldi AEM, Barcelos Junior MND, Veras CAG (2015) Concept and design of the hybrid test-motor for development of a propulsive decelerator of SARA re-entry capsule. Paper presented 51st AIAA/SAE/ASEE Joint Propulsion Conference. AIAA; Orlando, Florida, United States. https://doi.org/10.2514/6.2015-3941

ASTM E285-08 (2008) Standard test method for oxyacetylene ablation testing of thermal insulation materials. West Conshohocken: ASTM International. https://doi.org/10.1520/E0285-08

Barros EA, Filho GP, Gregori ML, Costa e Silva SF, Charakhovski LI, Maciel HS (2009) Thermal response and ablation characteristics of quartz-phenolic and carbon-phenolic composites. Paper presented COBEM 2009. International Congress of Mechanical Engineering. COBEM; Gramado, Rio Grande do Sul, Brazil.

Chapman AJ (1966) Evaluation of several silicone, phenolic, and epoxy base heat-shield materials at various heat transfer rates and dynamic pressures (technical report). Washington: NASA.

Donskoy AA (1996) Elastomeric heat-shielding materials for internal surfaces of missile engines. Inter J Polymeric Mater 31(1-4):215-236. https://doi.org/10.1080/00914039608029377

Favaloro M (2000) Ablation materials. In: Kirk-Othmer Encyclopedia of Chemical Technology. Hoboken: John Wiley \& Sons. https://doi.org/10.1002/0471238961.0102120106012201.a01

Kim ES, Kim EJ, Shim JH, Yoon J-S (2008) Thermal stability and ablation properties of silicone rubber composites. J Appl Polym Sci 110(2):1263-1270. https://doi.org/10.1002/app.28633

Kim ES, Lee TH, Shin SH, Yoon J-S (2011) Effect of incorporation of carbon fiber and silicon carbide powder into silicone rubber on the ablation and mechanical properties of the silicone rubber-based ablation material. J Appl Polym Sci 120(2):831838. https://doi.org/10.1002/app.33139

Koo JH, Miller MJ, Weispfenning J, Blackmon C (2011) Silicone polymer composites for thermal protection system: fiber reinforcements and microstructures. J Compos Mater 45(13):1363-1380. https://doi.org/10.1177/0021998310381536

Mazetti A, Merotto L, Pinarello G (2016) Paraffin-based hybrid rocket engines applications: A review and a market perspective. Acta Astronaut 126:286-297. https://doi.org/10.1016/j.actaastro.2016.04.036

Milhomem GP, Nunes APCP, Andrianov A, Shynkarenko O, Lee J (2017) Experimental studies of heat insulation materials for hybrid propellant rocket motors. Paper presented 24th ABCM International Congress of Mechanical Engineering. ABCM; Curitiba, Paraná, Brazil. https://doi.org/10.26678/ABCM.COBEM2017.COB17-1706

Miller MJ, Koo JH, Wilson D, Beckley DA (1994) Effect of reinforcements in a silicone resin composite. Paper presented 32nd Aerospace Sciences Meeting and Exhibit. AIAA; Reno, Nevada, United States. https://doi.org/10.2514/6.1994-787

Natali M, Kenny JM, Torre L (2016) Science and technology of polymeric ablative materials for thermal protection systems and propulsion devices: A review. Prog Mater Sci 84:192-275. https://doi.org/10.1016/j.pmatsci.2016.08.003 
Nunes APCP, Milhomem GP, Rispoli VC, Andrianov A (2017) Application of an inverse method for the estimation of heat flux in low-thrust hybrid propellant rocket motor and its analytical validation. Paper presented XXXVIII Iberian LatinAmerican Congress on Computational Methods in Engineering. CILAMCE; Florianópolis, Santa Catarina, Brazil.

Oyumi Y (1998) Ablation characteristics of silicone insulation. J Polym Sci A Polym Chem 36(2):233-239. https://doi. org/10.1002/(SICI)1099-0518(19980130)36:2\%3C233::AID-POLA4\%3E3.0.CO;2-S

Schmidt DL (1965) Ablative plastics and elastomers in chemical propulsion environments. Wright-Patterson Air Force Base. Ohio: Air Force Materials Laboratory, Research and Technology Division, Air Force Systems Command.

Schmidt DL (1969) Ablative polymers in aerospace technology. J Macromol Sci - Chem 3(3):327-365. https://doi. org/10.1080/10601326908053818

Twichell SE, Keller Junior RB (1976) Solid rocket motor internal insulation (NASA-SP-8093) (Technical Report). Washington: NASA.

Yang D, Zhang W, Jiang B (2013a) Ceramization and oxidation behaviors of silicone rubber ablative composite under oxyacetylene flame. Ceram Int 39(2):1575-1581. https://doi.org/10.1016/j.ceramint.2012.07.109

Yang D, Zhang W, Jiang B, Guo Y (2013b) Silicone rubber ablative composites improved with zirconium carbide or zirconia. Compos Part A Appl Sci Manuf 44:70-77. https://doi.org/10.1016/j.compositesa.2012.09.002

Youren JW (1971) Ablation of elastomeric composites for rocket motor insulation. Composites 2(3):180-184. https://doi. org/10.1016/0010-4361(71)90959-1

Yu L, Zhou S, Zou H, Liang M (2014) Thermal stability and ablation properties study of aluminum silicate ceramic fiber and acicular wollastonite filled silicone rubber composite. J Appl Polym Sci 131(1):39700. https://doi.org/10.1002/app.39700

Zhang G, Wang F, Huang Z, Dai J, Shi M (2016) Improved ablation resistance of silicone rubber composites by introducing montmorillonite and silicon carbide whisker. Materials 9(9):723. https://doi.org/10.3390/ma9090723

Zhou W, Yang H, Guo X, Lu J (2006) Thermal degradation behaviors of some branched and linear polysiloxanes. Polym Degrad Stabil 91(7):1471-1475. https://doi.org/10.1016/j.polymdegradstab.2005.10.005

Zhou C, Yu L, Luo W, Chen Y, Zou H, Liang M (2015) Ablation properties of aluminum silicate ceramic fibers and calcium carbonate filled silicone rubber composites. J Appl Polym Sci 132(11):41619. https://doi.org/10.1002/app.41619

Zweben C (2006) Composite materials. In: Kutz M, editor. Mechanical Engineers' Handbook. Materials and Mechanical Design. Hoboken: John Wiley \& Sons. p. 380-417. https://doi.org/10.1002/0471777447.ch10 